\title{
然
}

\section{EL LARGO CAMINO DE LA ADOPCIÓN DEL PAGO DIGITAL EN ESPAÑA}

El objetivo es visibilizar el retraso que muestra España en la adopción de alternativas al efectivo en las transacciones de pago cotidianas e identificar los factores y motivaciones que puedan explicar esta circunstancia. A partir del análisis del Global Findex Database 2017, de las estadísticas de pagos minoristas del Banco Central Europeo, de estudios de mercado especializados, así como del experimento social Cantabria Pago Digital, se muestra el patrón de comportamiento en materia de pagos cotidianos en España en términos comparados. La definición y comunicación explícita de un objetivo de política pública en materia de pagos digitales, el diseño y establecimiento de incentivos coherentes, la coordinación entre agentes y el fortalecimiento de las habilidades financieras y digitales de la población son, a la vista de los datos, condiciones necesarias para una adopción más ágil.

Palabras clave: transformación digital, pagos cotidianos, dinero en efectivo, incentivos, eficiencia, acceso y uso, educación financiera.

Clasificación JEL: E47, E51.

\section{Introducción}

Cada tres años, en el mes de abril, el Banco Mundial publica el informe Global Findex, que, desde una perspectiva de demanda —esto es, acudiendo y preguntando directamente a las personas que conforman el público objetivoestima el grado de inclusión financiera de la población en más de 140 países, entre los que se encuentra España. En abril de 2017 se conocieron los resultados de su III edición, que sitúan de nuevo a España en una posición de inclusión prácticamente universal en cuanto al

\footnotetext{
* Consultora de Analistas Financieros Internacionales.

Versión de septiembre de 2018.
}

acceso a servicios financieros se refiere, estando el acceso definido como la situación de tenencia individual o compartida de una cuenta de ahorro o cuenta corriente en una entidad financiera, situación en la que declara encontrarse el 94 por 100 de la población española de quince años o más.

Es de esperar que en los próximos meses ese 6 por 100 que declara no poseer una cuenta lo haga aprovechando las nuevas condiciones que establece la trasposición de la Directiva 92/2014/UE ${ }^{1}$, en virtud de la cual $\triangleright$

\footnotetext{
1 Real Decreto-Ley de 19/2017, de 24 de noviembre, el cual garantiza el acceso a una cuenta de pago con derecho a realizar operaciones básicas como depósitos en cuenta, retirada de efectivo, transferencias o pagos con tarjeta, entre otros, y el proyecto de Orden Ministerial sobre servicios, comisiones de cuentas de pago básicas, procedimiento de traslado y comparadores.
} 
las entidades financieras españolas deben ofrecer al menos un producto (cuenta de pago básica) que permita realizar un catálogo mínimo de transacciones de pago digital, a un precio máximo de tres euros al mes. Es, asimismo, razonable pensar que ese 6 por 100 de adultos españoles no bancarizados vive y convive inmerso en un mundo de dinero efectivo. También es razonable pensar que buena parte del 94 por 100 de los que sí declaran estar bancarizados cuenta con medios de pago alternativos al efectivo, como tarjetas de pago, y que los utilizan. Pues bien, si la primera parte del supuesto es cierta en gran medida -Global Findex 2017 desvela que el 85 por 100 de la población adulta española dispone de una tarjeta de débito-, la segunda, lamentablemente, no lo es, como veremos a continuación, comportamiento que no resulta coherente con el momento de transformación digital en que nos encontramos inmersos a todos los niveles como sociedad. Mostrar el desfase entre acceso y uso de medios de pago alternativos al efectivo, identificar las causas que pueden estar motivando este comportamiento y sugerir algunas recomendaciones para corregir esta anomalía es el objetivo múltiple del presente trabajo.

\section{El tránsito del efectivo hacia métodos electrónicos o digitales de pago}

\subsection{Transformación digital en pagos de la mano de la directiva PSD2}

Nos encontramos inmersos en un momento singular de cambio tecnológico y transformación digital que inevitablemente obliga a adaptar la forma en que hacemos todo tipo de actividades.
Ya en 2014, la Unión Europea (UE), en la exposición de motivos de la Agenda Digital para Europa, que pretende ayudar a los ciudadanos y empresas de Europa a sacar el máximo partido de las tecnologías digitales, constató que la economía digital crecía siete veces más que el resto de la economía, un claro indicador de hacia dónde debemos dirigir los esfuerzos en la generación de habilidades, capacidades y competencias en un mundo global para no quedarnos al margen de la senda en que se materializa el crecimiento - la senda digital-. Son muchas las dimensiones a abordar en el reto de la digitalización, siendo una de ellas, aunque aparentemente insignificante, fundamental para avanzar: el pago, gesto cotidiano que todos y todas hacemos a diario y que en España se ha quedado anclado, por la forma en que lo realizamos mayoritariamente en el pasado. $Y$ es que las sociedades más avanzadas presentan una tendencia de reducción del uso del efectivo en sus vidas, algunas de ellas en un firme tránsito hacia sociedades independientes del dinero en papel y de la moneda metálica: en los países del norte de Europa apenas utilizan efectivo para realizar sus pagos cotidianos, mientras que en España aún hoy más de dos terceras partes de los pagos en el punto de venta se realizan en efectivo, por cerca del 90 por 100 del valor de los mismos.

Tanto es así que, a pesar de que hoy en día cualquier nuevo servicio ofertado en el mercado tiene una elevada probabilidad de ser diseñado de forma nativa para que su pago se realice exclusivamente por métodos electrónicos o digitales (pensemos, por ejemplo, en las numerosas soluciones de movilidad urbana compartida, o el más generalizado comercio electrónico, no permitiendo el pago en efectivo), algunos proveedores globales de este tipo de servicios, como Uber, han optado por aceptar efectivo $D$ 


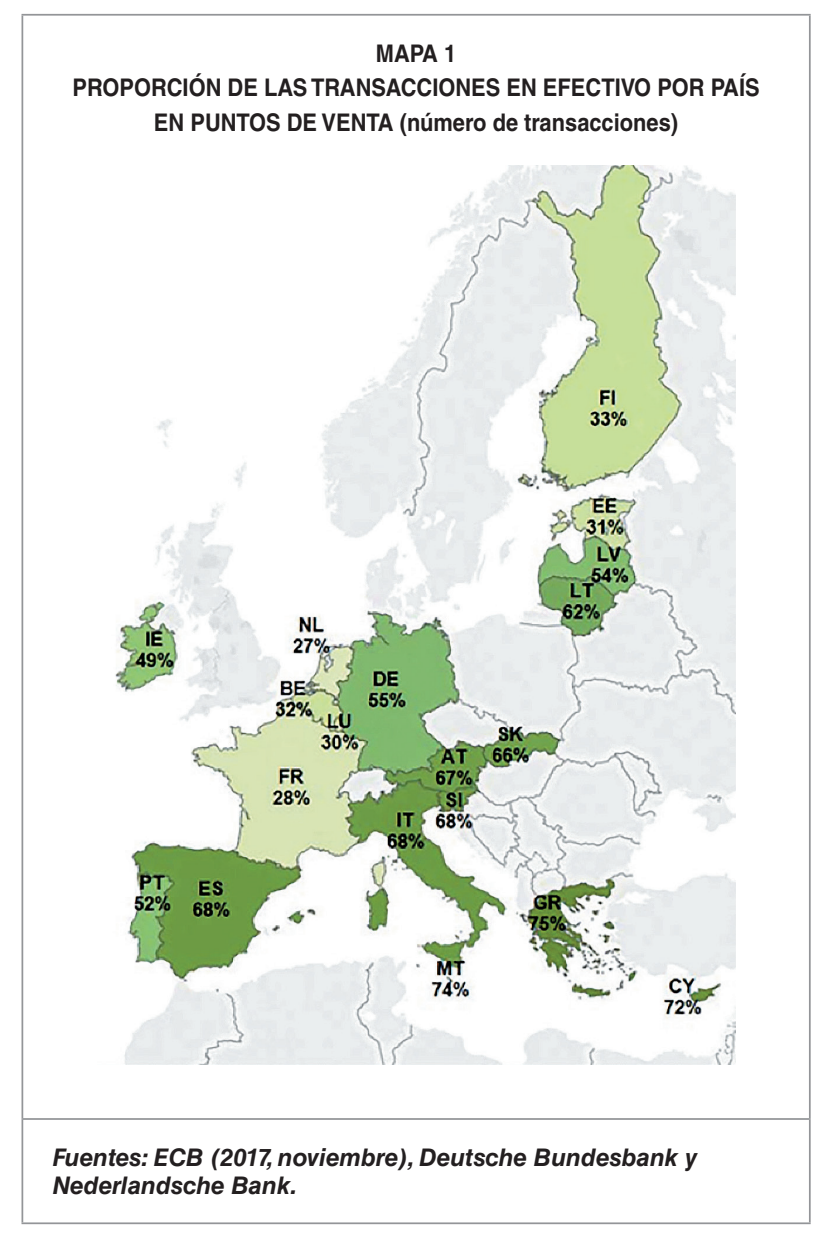

en España, con las implicaciones y complicaciones operativas que ello conlleva, a pesar de que la propia compañía señala en su página web que, «en la mayoría de las ciudades, Uber funciona sin pagos en efectivo» ${ }^{2}$. España forma parte, por tanto, de la excepción a una política corporativa global. ¿Es positivo o negativo el hecho de que Uber haya claudicado en España en uno de sus atributos más singulares, una experiencia 100 por 100 digital? Incorporar la aceptación del pago en efectivo como «reclamo» o política de marketing invita a pensar que sin él las ventas serían menores. Ello puede ocurrir porque los usuarios no disponen de medios alternativos al efectivo -algo que hemos constatado que no es el caso- o

\footnotetext{
2 Ver https://help.uber.com/h/cae4b926-03d6-4ebf-81c4-75953ef54c0c
}

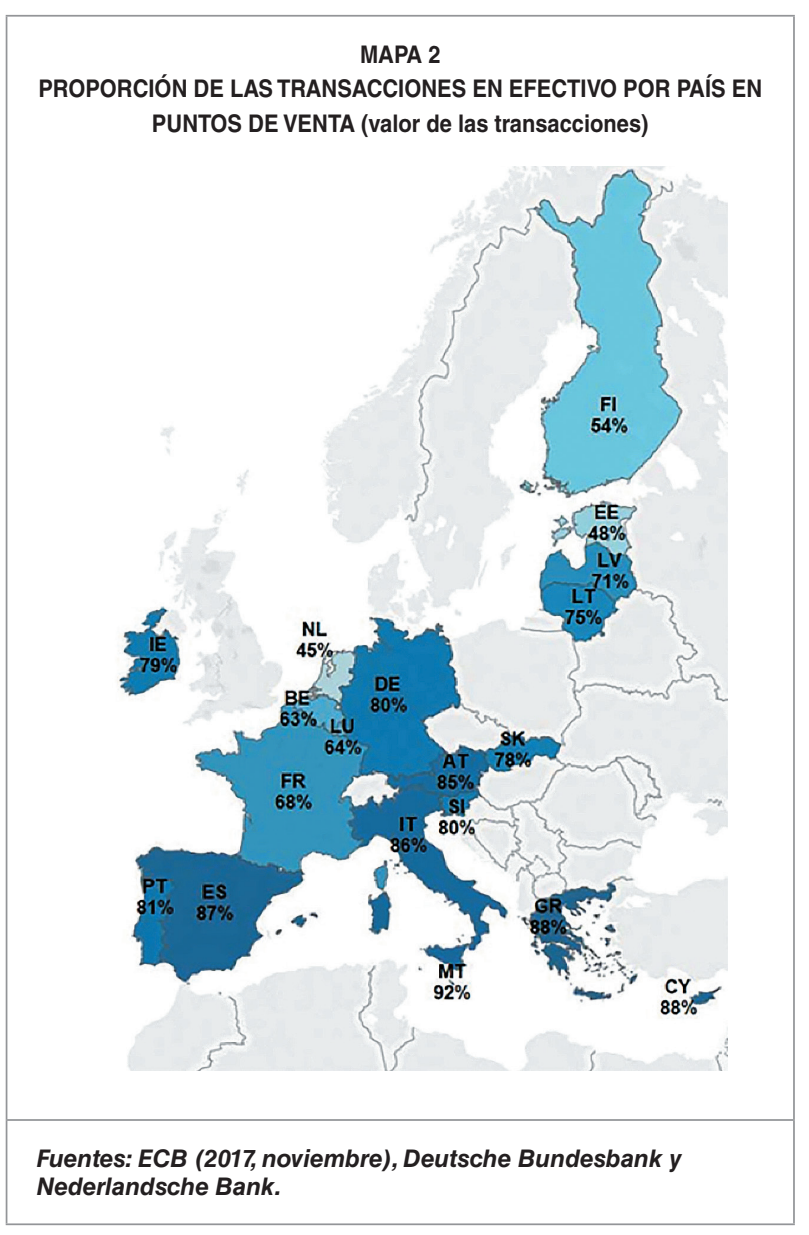

porque, teniéndolos, no los utilizan, ya sea por una decisión consciente, por desconocimiento y/o inseguridad o por falta de costumbre, porque la aceptación del pago digital no es universal en España.

Un razonamiento similar puede aplicarse al debate reciente sobre la menguante presencia de puntos físicos de entidades financieras en el entorno rural, en especial de cajeros automáticos para la distribución de dinero en efectivo, situación en la que se encontrarían, de acuerdo con el Banco de España (2018), cerca de la mitad de los municipios españoles (4.109), que albergan un 2,7 por 100 de la población total. Nuestra tesis es que el pago electrónico o digital eliminaría los efectos de «escasez» de efectivo y las dificultades de su distribución, ya que su universalización convertiría al dinero en $\triangleright$ 


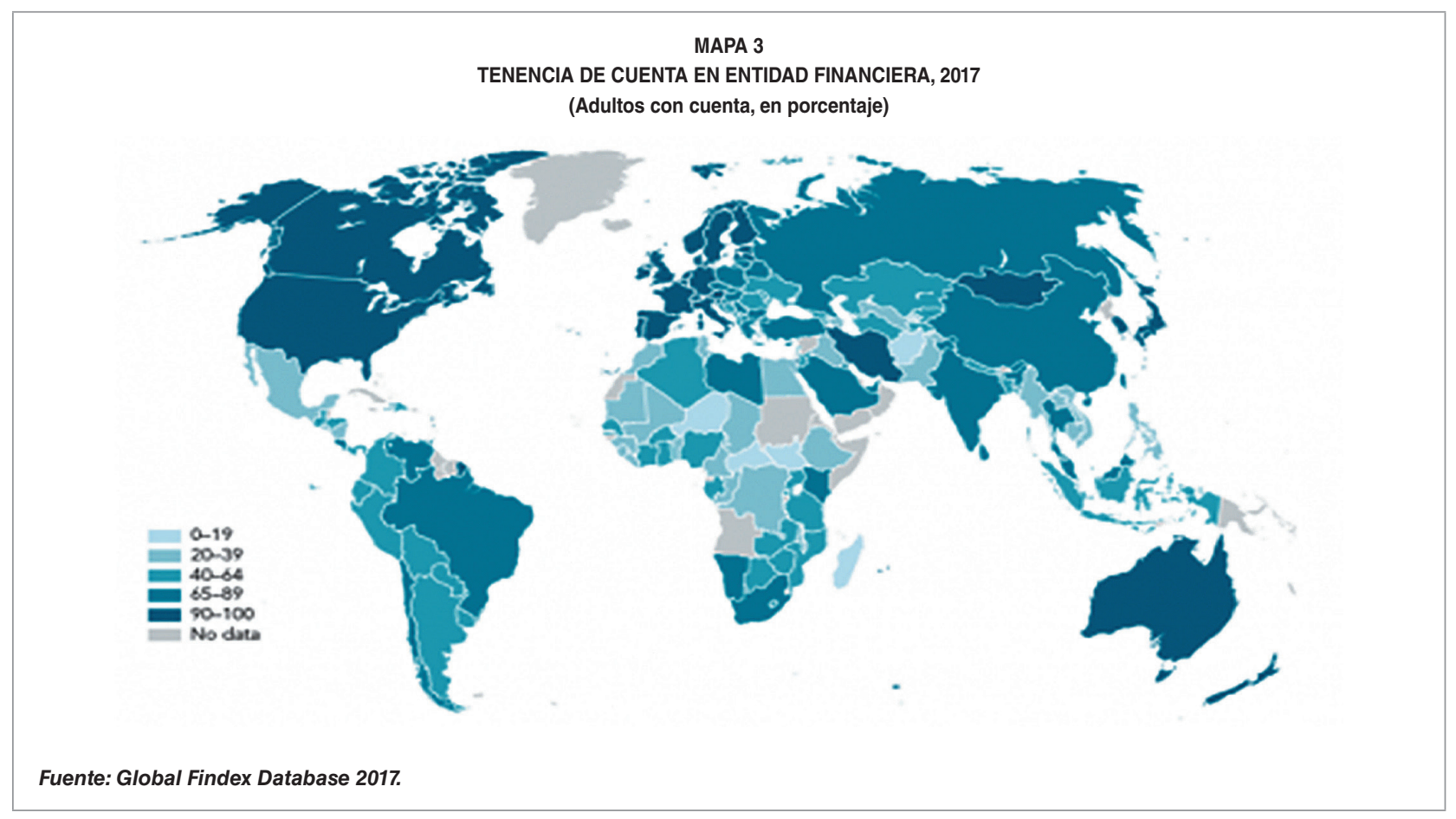

efectivo en un elemento absolutamente prescindible para el normal desarrollo de las actividades económicas.

No en vano, las autoridades europeas llevan años trabajando para que todos los ciudadanos europeos contemos con formas seguras y convenientes para realizar nuestros pagos y cobros en un contexto digital (nueva Directiva de Servicios de Pago o PSD2), provistas por un creciente número y variedad de agentes - más allá de los proveedores tradicionales de servicios de pago, esto es, los bancos- que contribuyan a incrementar las necesarias ganancias de eficiencia, la transparencia, la protección al cliente y la innovación. El arraigo que se observa en España del uso del dinero en efectivo ralentiza la consecución de dichas ganancias, o directamente impide que se produzcan. $Y$ son pocas o muy tenues las señales que emiten los agentes desde el sector público o privado llamados a revertir esta predominancia.

\section{Una comparativa europea en materia de pagos cotidianos}

\subsection{Acceso y equipamiento}

La comparativa más inmediata y razonable es la que nos sitúa como país en relación al contexto geográfico y político más cercano, esto es, la zona euro o la Unión Europea. Con el objeto de comenzar el análisis con una panorámica global, recurrimos de nuevo al ya mencionado informe Global Findex, en particular a la imagen que ratifica la prácticamente total universalización de la tenencia de cuentas bancarias entre la población adulta española (Mapa 3).

Acudiendo a las estadísticas publicadas por el Banco Central Europeo (BCE), complementamos el dato anterior con los niveles de equipamiento desde la perspectiva de la aceptación -TPV o datáfonos- superior a la media europea, con alrededor de 35.000 TPV por $\triangleright$ 


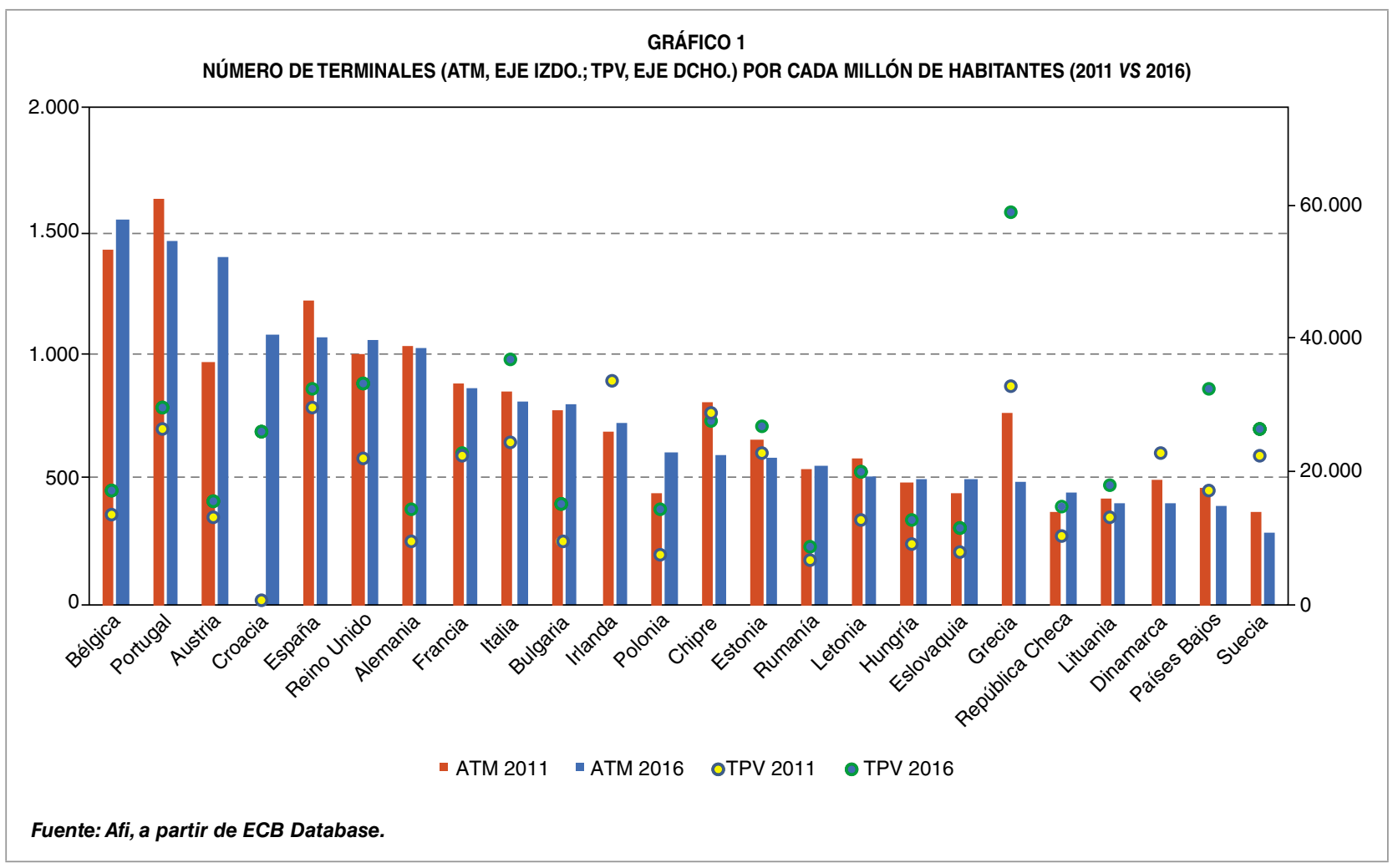

millón de habitantes, y mostrando un crecimiento positivo en el periodo 2011-2016 en esta variable. Por su parte, el crecimiento en la red de ATM muestra un comportamiento gradualmente menguante, al compás del registrado en la mayoría de los países de la UE reflejados en el Gráfico 1.

En consecuencia, tanto las personas como los puntos de venta en España se encuentran comparativamente bien equipados —un buen nivel de acceso-, con medios de pago alternativos al efectivo.

\subsection{Uso}

Es precisamente en la dimensión de las estadísticas sobre pagos que permiten conocer el uso dado a los medios de pago y cobro disponibles donde aparecen los primeros indicios de diversidad de comportamientos ante el pago entre los consumidores europeos, y en las que España comienza a descender puestos con preocupante rapidez, situándose en rangos muy alejados de los que se esperaría por el avanzado nivel de acceso mostrado.

El Gráfico 2 desvela que si bien cerca de nueve de cada diez adultos españoles cuentan con una tarjeta de pago - débito fundamentalmente- -, solo realizaron en dicho año una media de 74 pagos con tarjeta al año por persona (menos de 1,5 pagos a la semana), muy por debajo de la media de la UE (117 pagos con tarjeta per cápita al año) e incluso de la zona euro (97). De este modo, España se situaba entre los países con mayor nivel de acceso y equipamiento, mientras que en cuanto al uso solo se encontraba por encima de algunos países de Europa del Este, Alemania, Italia, Grecia y otros pequeños como Malta y Chipre, y muy por detrás de los líderes: Dinamarca y Suecia (> 300); Finlandia y Reino Unido (> 250); Países $\triangleright$ 


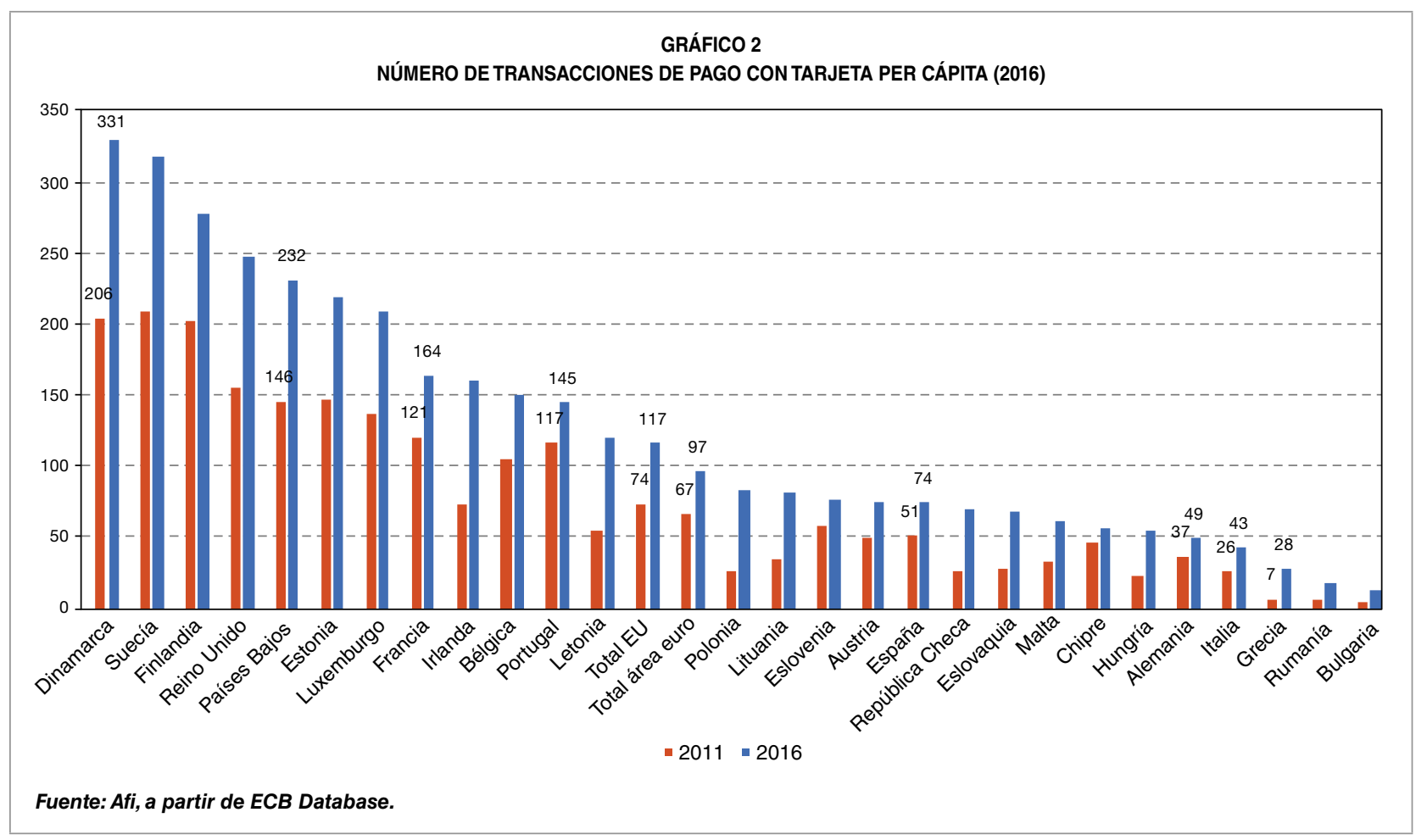

Bajos, Estonia y Luxemburgo (> 200). La situación en términos de valor como porcentaje del PIB es similar a la mostrada por la intensidad de uso del pago con tarjeta.
En términos dinámicos, el comportamiento mostrado por España en el periodo 2011-2016 muestra asimismo un ritmo comparativamente lento, no solo por debajo del registrado en $\triangleright$

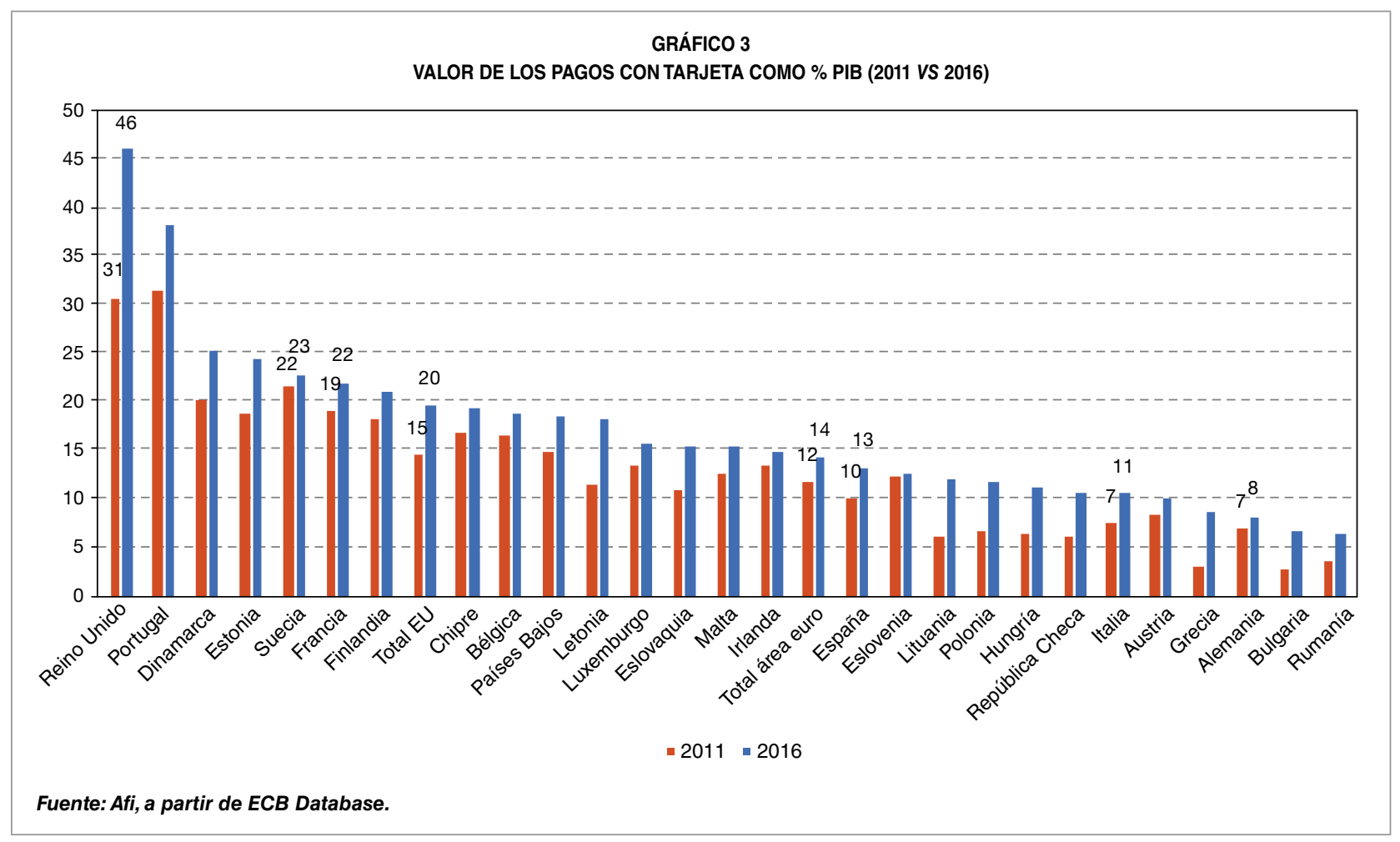




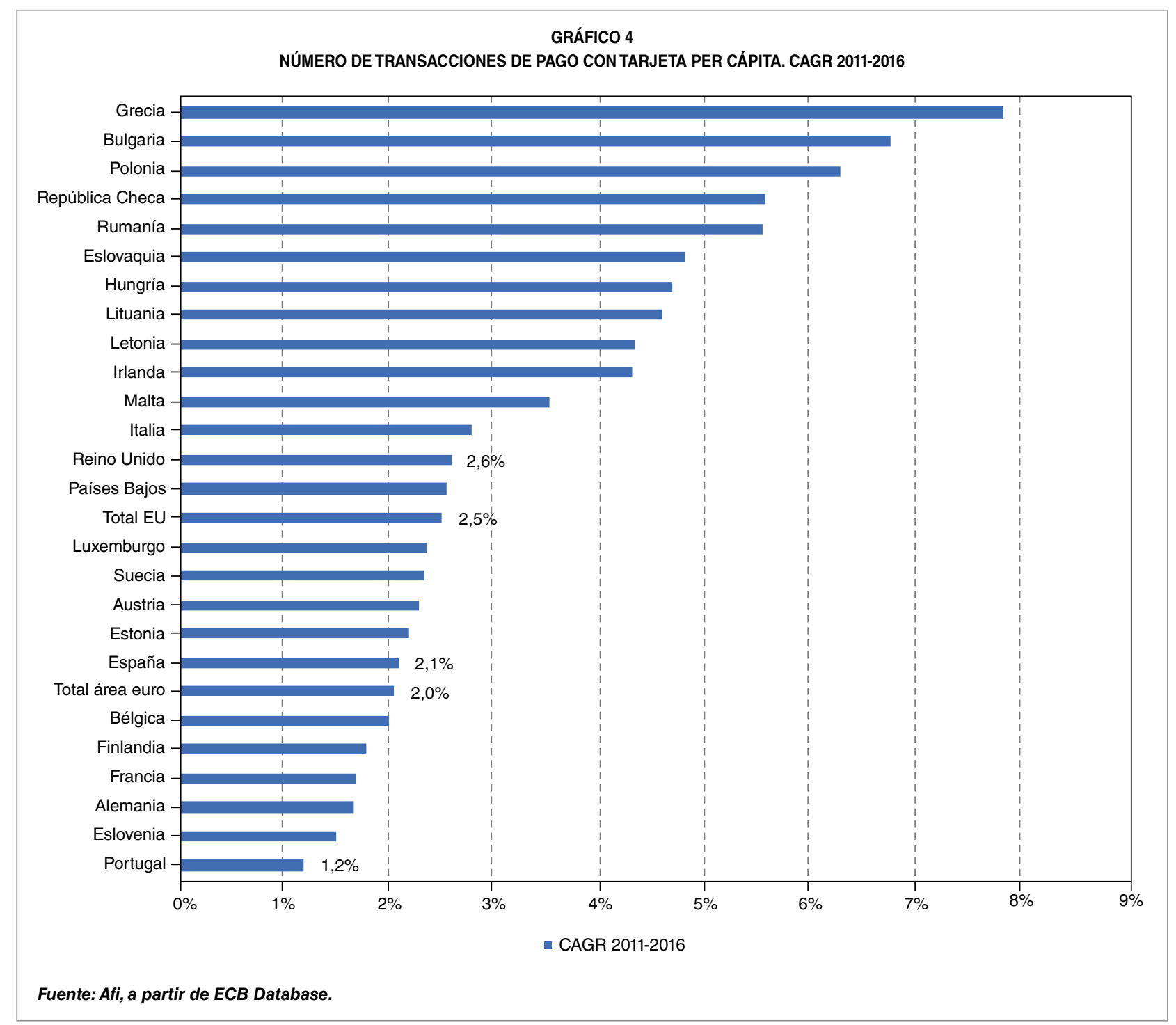

promedio por los países de la UE, sino del de aquellos países que se situaban junto a España a la cola en términos de transaccionalidad y de los que se espera, como así registran, un mayor crecimiento (Gráfico 4).

Esta misma baja transaccionalidad en pagos con tarjeta se traduce en un reducido uso de los equipamientos con que contamos. En el Gráfico 5 puede observarse el reducido uso al que se someten los TPV en España en términos comparados: cada TPV instalado en España recibe algo menos de 2.200 transacciones de pago al año (concretamente en 2016), cuando en Holanda y Dinamarca son cerca de 14.000 las registradas ese año, un 600 por 100 más. Los TPV británicos reciben tres veces más operaciones al año que los TPV españoles. Y los portugueses, un 66 por 100 más.

Las anteriores cifras se pueden traducir en términos de rentabilidad de los equipamientos instalados considerando el valor recibido por cada dispositivo/datáfono. Mientras que en España cada TPV instalado recibe en promedio al año (2016) 95.000 euros, en Dinamarca estos superan el medio millón de euros, y se acercan a esa cifra los TPV holandeses y $\triangleright$ 

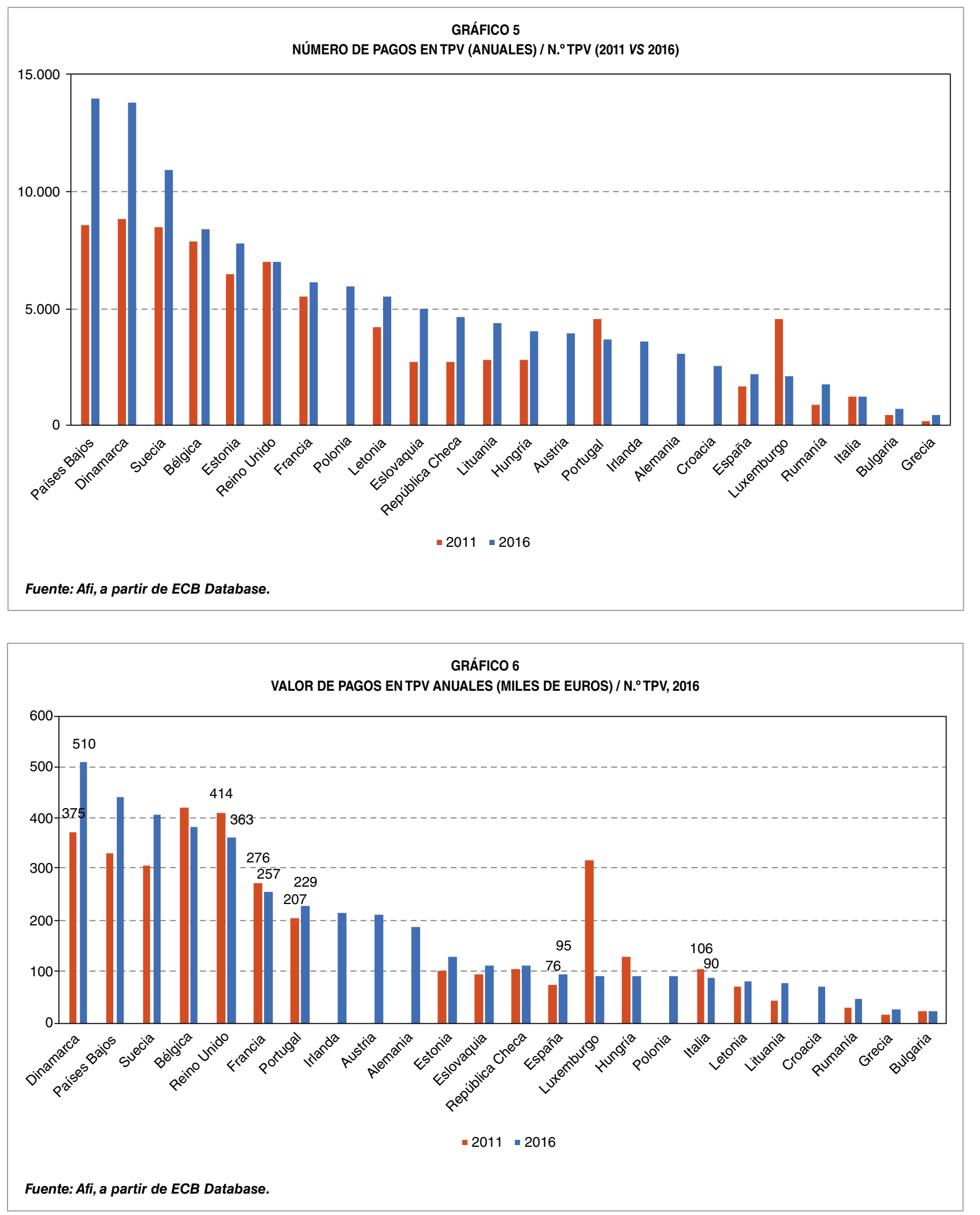

los suecos. La reducida «rentabilidad» generada por los TPV instalados en España puede observarse en el Gráfico 6.
Otro indicador que resulta ilustrativo analizar es el que informa del momento en que se produce un hito consecuente con la digitalización $\triangleright$ 


\begin{tabular}{|c|c|c|}
\hline \multicolumn{3}{|c|}{$\begin{array}{l}\text { GRÁFICO } 7 \\
\text { VALOR DE PAGOS EN TPV VS VALOR DE RETIROS EN ATM }\end{array}$} \\
\hline ESPAÑA (2002-2016) & PORTUGAL (2005-2016) & BÉLGICA (2001-2015) \\
\hline 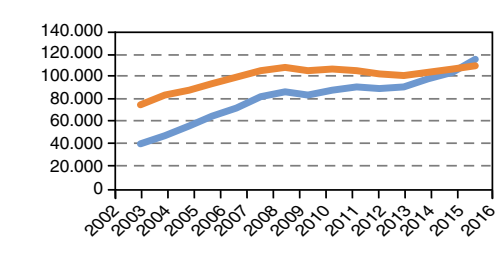 & $\begin{array}{l}70.000 \\
60.000 \\
50.00 \\
40.000 \\
30.00 \\
20.000 \\
10.000\end{array}$ & 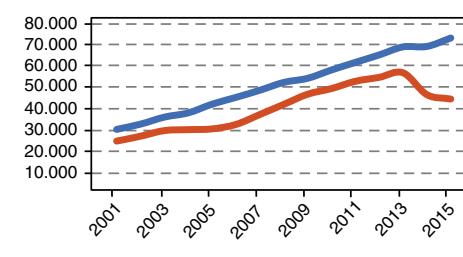 \\
\hline FRANCIA (2011-2015) & ALEMANIA (2001-2015) & ITALIA (2001-2015) \\
\hline 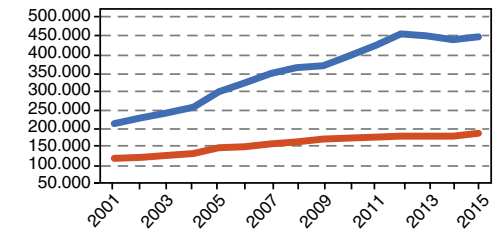 & 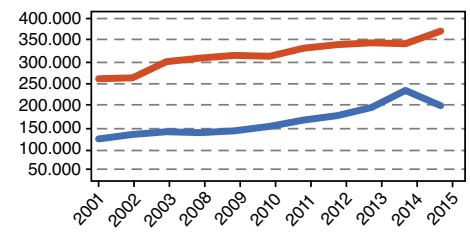 & $\begin{aligned} 200.000 \\
180.000 \\
1960.000 \\
120.000 \\
120.000 \\
100.000 \\
50.000 \\
60.000 \\
40.000 \\
20.000\end{aligned}$ \\
\hline PAÍSES BAJOS (2001-2015) & SUECIA (2004-2015) & REINO UNIDO (2001-2015) \\
\hline 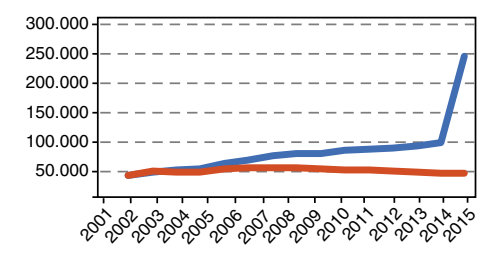 & 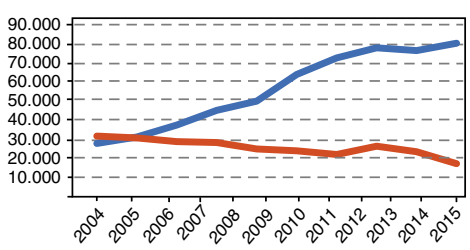 & 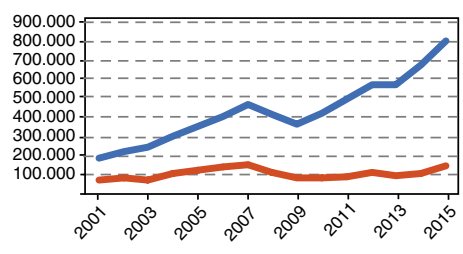 \\
\hline & $\begin{array}{l}\text { _ Valor pagos en TPV (millones de } € \text { ) } \\
\text { Valor retiros en ATM (millones de } € \text { ) }\end{array}$ & \\
\hline & & \\
\hline
\end{tabular}

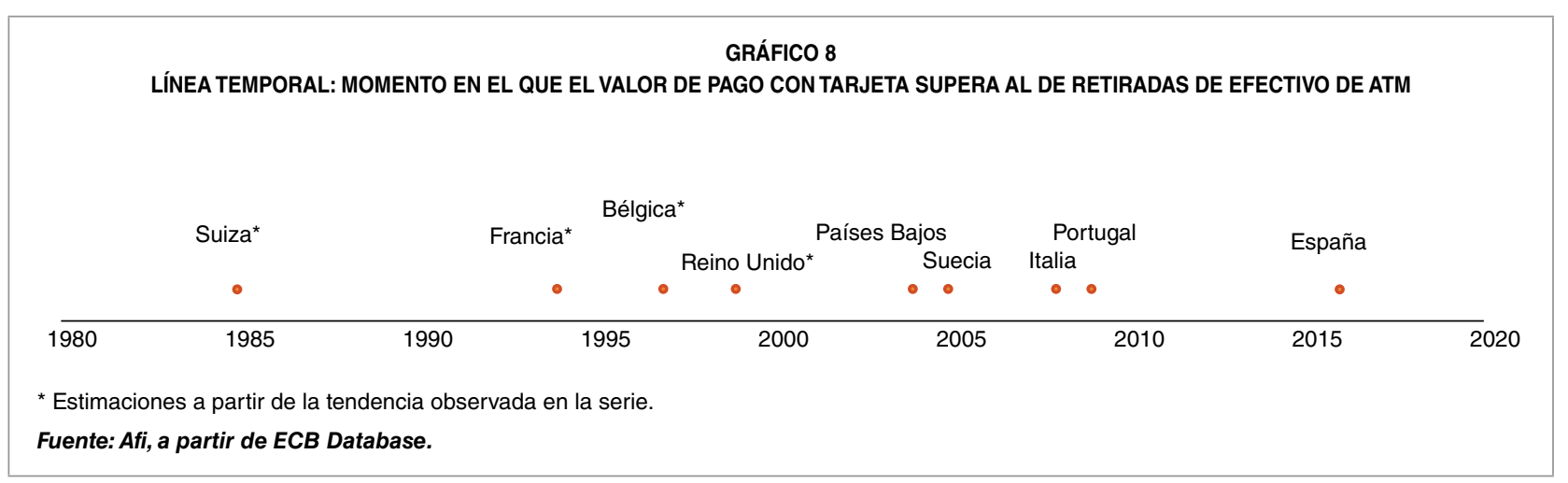

de los pagos: cuando el valor de los pagos con tarjeta en TPV supera al valor de los retiros de efectivo de ATM. Los Gráficos 7 y 8 evidencian el retraso identificado en España: mientras que aquí el hito «histórico» señalado se produjo en 2016, en el resto de países — salvo en Alemania, donde aún no se ha producido — lo hizo en años e incluso décadas anteriores. 


\section{4. ¿Por qué en España es tan distante el acceso del uso? ¿Será que faltan incentivos?}

Ya hemos visto que en España, para pagos cotidianos o de bajo valor en puntos de venta (establecimientos comerciales, pequeño comercio, hostelería y servicios), el efectivo es el medio de pago aparentemente preferido, a la luz del medio en que finalmente se materializan dichas transacciones. Pero ha de tenerse en cuenta que en el pago intervienen dos partes - la que cobra y la que paga-, y es, hasta la fecha, decisión soberana del punto de venta aceptar o no medios de pago alternativos al efectivo (tarjeta, fundamentalmente). Esta realidad arroja situaciones como las recogidas en el Gráfico 9: para más de la mitad de los tenedores de tarjeta $(52,6$ por 100$)$ es habitual encontrar establecimientos comerciales que no aceptan el pago con tarjeta, mientras que para tres de cada cuatro lo habitual es la exigencia de un importe mínimo para que dicha aceptación sea efectiva. Esto es, el establecimiento dispone de un dispositivo para aceptar pago con tarjeta, pero solo lo ofrece a partir de determinado importe, absolutamente discrecional (la decisión y el importe) ${ }^{3}$.

En el comercio online, por el contrario, apenas un 16 por 100 de tenedores de tarjeta declara no poder utilizarla para compras o pagos.

Esta realidad tan frecuente en establecimientos físicos tiene, afortunadamente, los días

3 Si España se encuentra entre los países amonestados por la Comisión Europea por no haber traspuesto la PSD2 en tiempo y forma, fue por el contrario el primero en adoptar la aplicación del Reglamento de Tasas de Intercambio para pagos con tarjeta (Interchange Fee Regulation, IFR por sus siglas en inglés), en vigor desde septiembre de 2014 mediante la Ley 18/2014, imponiendo desde entonces los siguientes límites máximos: 0,3 por 100 del importe de la compra para las tarjetas de crédito o 0,2 por 100 para las de débito, con un máximo de 7 céntimos por transacción en las de débito, y, en operaciones de hasta 20 euros, bajan a 0,2 y 0,1 por 100 respectivamente. contados desde que, el pasado 18 de mayo, el Consejo de Ministros aprobara el texto del proyecto de ley de transposición de la nueva Directiva de Servicios de Pago (PSD2) que sustituirá la Ley de Servicios de Pago de 2009 una vez superados los trámites parlamentarios. En el texto del proyecto se ha incluido ex novo la obligación de que todo establecimiento comercial o proveedor de servicios que reciba pagos superiores a los 30 euros directamente del público ofrezca un medio de cobro alternativo al efectivo, sin explicitar que deban ser tarjetas de pago u otro medio. Dicho esto, la motivación de que sean 30 euros y no otra cifra -o ninguna- el límite a partir del cual se activa dicha exigencia no queda explicado en el texto, y hubiera sido deseable renunciar a límites mínimos, especialmente en una norma con rango de ley. Es más, debería considerarse el derecho del ciudadano a ser digital a la hora de realizar pagos, independientemente del importe, dentro de una gama razonable y básica.

\subsection{Necesidad de diagnosticar, emitir señales claras y diseñar incentivos inteligentes}

En los últimos meses se han celebrado, inspiradas en la iniciativa pionera Cantabria Pago Digital (www.cantabriapagodigital.es), otras desarrolladas en pequeños municipios de Álava ${ }^{4}$ y Castellón ${ }^{5}$. La sucesión de experiencias piloto denota y corrobora que el tránsito al pago digital en España es un reto que necesita acompañamiento y apoyo; que queda mucho por hacer, en especial garantizar el $\triangleright$

\footnotetext{
4 http://www.elmundo.es/pais-vasco/2018/04/17/5ad62c6cca47418c 228b4577.html

5 https://www.lavanguardia.com/local/valencia/20180409/ 442381524734/caixabank-pone-en-marcha-un-proyecto-para-situar-amorella-castellon-en-la-vanguardia-de-los-pagos-digitales. $h$ tml
} 


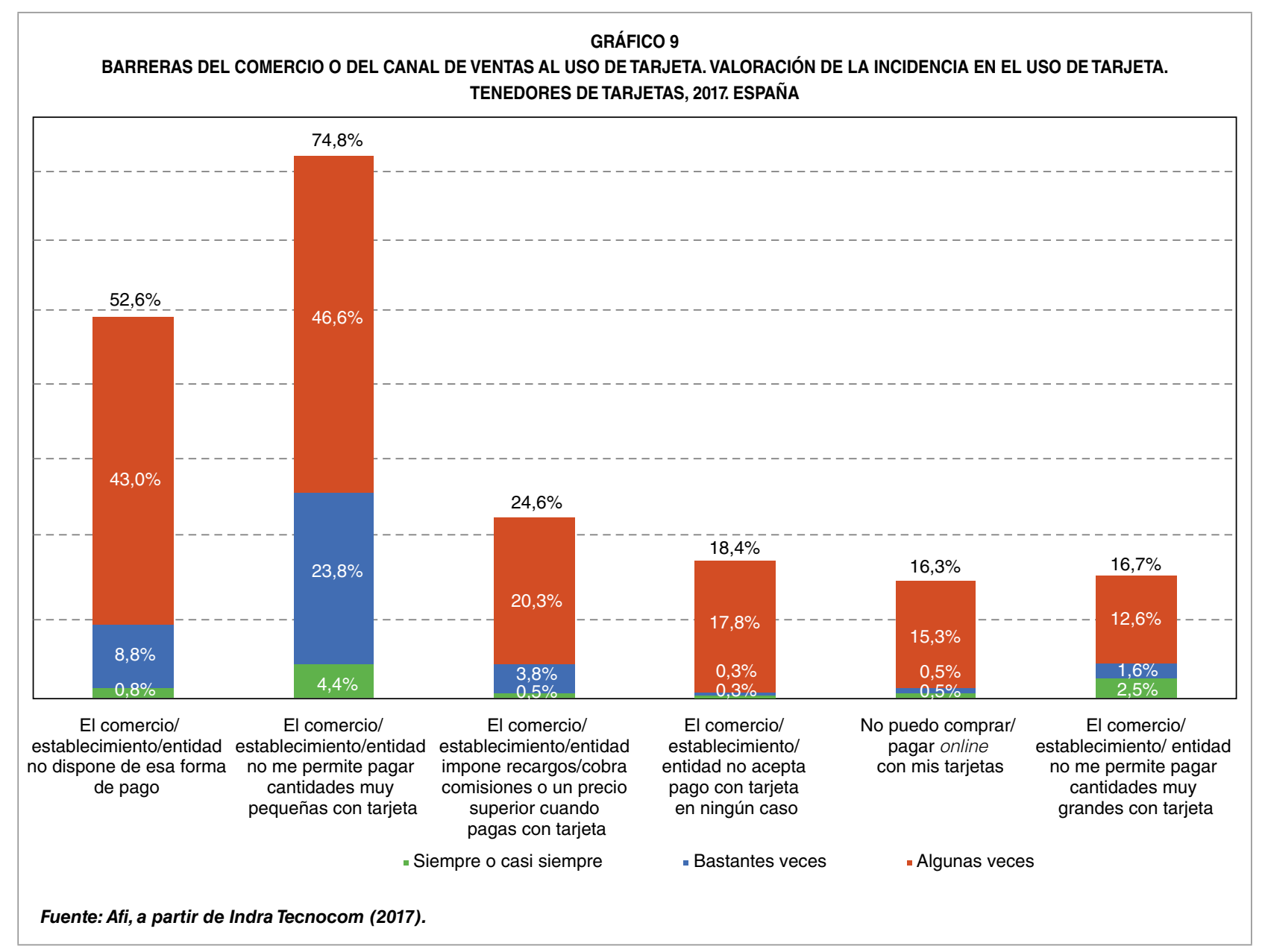

equipamiento, pero sobre todo la adopción y el uso generalizado, universal, del pago digital, y que es un camino en el que tanto Administraciones Públicas, proveedores de servicios de pago y ciudadanos deben transitar de forma coordinada. Dicha coordinación requiere contar con señales e incentivos inequívocos. En este sentido, situaciones como la que vivimos desde diciembre de 2016, cuando se aprobó en Consejo de Ministros la reducción del límite para pagos en efectivo a 1.000 euros (desde los 3.000 euros anteriores), y que no se ha aplicado aún casi dos años después, no contribuyen positivamente. Asimismo, las AAPP deben maximizar el efecto catalizador que ostentan a partir de los comportamientos y hábitos de pago en sus ámbitos de influencia más cercanos (tributos, multas, cánones, pagos por servicios, servicios concesionados, etcétera).

El fortalecimiento de las capacidades y habilidades financieras y digitales de particulares y pequeños establecimientos es asimismo condición necesaria para mejorar la confianza, la seguridad percibida y el empoderamiento de los ciudadanos en un entorno creciente e inevitablemente digital. La experimentación práctica para la resolución de dudas y familiarización con las nuevas soluciones de pago es una tarea que las entidades proveedoras de servicios de pago, fundamentalmente los bancos, habrían de incorporar en sus procedimientos, $D$ 
junto con un mayor grado de transparencia en las condiciones ofertadas y contratadas.

\section{Conclusiones y recomendaciones}

Los resultados observados animan a afirmar que es preciso, para avanzar en la universalización del pago digital en España:

- Garantizar el acceso de todos y todas a medios de pago digital asequibles, para lo cual la Comisión Europea y el Parlamento consideraron necesario emitir la Directiva 92/2014 sobre cuentas de pago básicas.

- Animar a la adopción y el uso universal, para lo cual es aún necesario garantizar que la aceptación es asimismo universal, condición que queda parcialmente contemplada en el proyecto de trasposición de la PSD2, a partir de 30 euros.

- Garantizar que la población esté adecuadamente informada y que conoce las alternativas a su alcance, para lo que es necesario mejorar los requisitos de transparencia -incluso equiparando a pequeños comercios y negocios con el tratamiento que reciben particulares-, así como mejorar sustancialmente las habilidades financieras y digitales de la población.

- Identificar y superar situaciones en la que los ciudadanos se ven obligados a recurrir al uso del efectivo estando equipados para pagar de formas alternativas.

El cumplimiento de estos condicionantes que permitan acortar el camino de la adopción del pago digital en España requiere de un impulso público-privado en el que las Administraciones Públicas sean catalizadoras y ejemplo de transformación digital en materia de pagos.

\section{Bibliografía}

[1] AFI (2017). Tránsito a la Economía Digital: Diagnóstico de las prácticas de pago de Suances. Disponible en: http://www.afi.es/afi/ libre/pdfs/CantabriaPD/Resultados Diagn\%C3\%B3stico_Pr\%C3\%A1cticas _ Pago_Suances.pdf [Recuperado: 2018, 13 de septiembre].

[2] AFI (2018). Cantabria Pago Digital. La primera experiencia cashless en España. Informe de resultados. Disponible en: http://www.afi.es/ afi/libre/pdfs/CantabriaPD/Cantabria-PagoDigital_Experiencia-Cashless_Informe-Final. pdf [Recuperado: 2018, 13 de septiembre].

[3] BANCO MUNDIAL (2018). The Global Findex Database 2017. Disponible en: https://globalfindex.worldbank.org/\#data_sec_focus [Recuperado: 2018, 13 de septiembre].

[4] ESSELINK, H. y HERNÁNDEZ, L. (2017). «The use of cash by households in the euro area». Occasional Paper Series. n.․ 201. European Central Bank. Disponible en: https://www.ecb. europa.eu/pub/pdf/scpops/ecb.op201.en.pdf [Recuperado: 2018, 13 de septiembre].

[5] EUROPEAN CENTRAL BANK (2018). Statisctics on Payment services and large-value and retail payment systems. Disponible en: https://www.ecb.europa.eu/stats/payment_ statistics/payment_services/html/index.en.ht$\mathrm{ml}$ [Recuperado: 2018, 13 de septiembre].

[6] EUROPEAN COMMISSION (2014). Directiva 2014/92/UE del Parlamento Europeo y del Consejo de 23 de julio de 2014 sobre la comparabilidad de las comisiones conexas a las cuentas de pago y el acceso a cuentas de pago básicas. Disponible en: https://eur-lex. europa.eu/legal-content/ES/TXT/ HTML/?uri=CELEX:32014L0092\&from $=E S$ [Recuperado: 2018, 13 de septiembre].

[7] EUROPEAN COMMISSION (2015). Directiva 2015/2366/UE del Parlamento Europeo y $\triangleright$ 
del Consejo de 25 de noviembre de 2015 sobre servicios de pago en el mercado interior (PSD2). Disponible en: https://eur-lex.europa. eu/legal-content/ES/TXT/HTML/? uri= CELEX:32015L2366\&from=es [Recuperado: 2018, 13 de septiembre].

[8] EUROPEAN COMMISSION (2018). European Semester Thematic Factsheet Undeclared Work. Disponible en: https://ec. europa.eu/info/sites/info/files/file_import/european-semester_thematic-factsheet_undeclared-work_en.pdf [Recuperado: 2018, el 13 de septiembre].

[9] INDRA (2017). Informe Indra Tecnocom sobre Tendencias en Medios de Pago 2017. Disponible en: https://www.indracompany. com/sites/default/files/d7//magenes/ Sectores/Servicios-Financieros/informeindratecnocom2017-web.pdf [Recuperado: 2018, 13 de septiembre].

[10] JIMÉNEZ, C. Y TEJERO, H. (2018). «Cierre de oficinas bancarias y acceso al efectivo en España». Revista de Estabilidad Financiera, n. - 34. Banco de España. Disponible en: $h$ ttps:// www.bde.es/f/webbde/GAP/Secciones/ Publicaciones/InformesBoletinesRevistas/ RevistaEstabilidadFinanciera/18/MAYO/ Articulo_Jimenez_Tejero.pdf [Recuperado: 2018, 13 de septiembre].

[11] LEY 18/2014, de 15 de octubre, de aprobación de medidas urgentes para el crecimiento, la competitividad y la eficiencia. BOE n.․ 252 , de 17 de octubre 2014. Disponible en: https:// www.boe.es/buscar/act.php?id=BOE-A2014-10517 [Recuperado: 2018, 13 de septiembre].

[12] LÓPEZ, V. y VIZCAÍNO, D. (2016). «Incentivos al uso de los medios de pago electrónico", en Transformación digital en los medios de pago. Papeles de Economía Española, n.․ 149, FUNCAS. Disponible en: https://www.funcas. es/Publicaciones/Sumario.aspx? I$d R e f=1-01149$ [Recuperado: 2018, 13 de septiembre].
[13] MINISTERIO DE ECONOMÍA Y EMPRESA (2018). Ley $X X / 2018$, de... de..., del mercado de servicios de pago. Disponible en: http:// www.mineco.gob.es/stfls/mineco/ministerio/ participacion_publica/audiencia/ficheros/ ECO_Tes_171222_AP_Ley_transposicion_ PSD2.pdf [Recuperado: 2018, 13 de septiembre].

[14] MINISTERIO DE ECONOMÍA Y EMPRESA (2018). Proyecto de Orden Sobre Servicios, Comisiones de Cuentas de Pago Básicas, Procedimiento de Traslado y Comparadores. Disponible en: https://d500.epimg.net/descargables/2018/07/17/917539dc37a8ddb7524ba03d50ef3430.pdf [Recuperado: 2018, 13 de septiembre].

[15] REAL DECRETO-LEY 19/2017, de 24 de noviembre, de cuentas de pago básicas, traslado de cuentas de pago y comparabilidad de comisiones. BOE n.. 287, de 25 de noviembre de 2017, pp. 114353 a 114367. Disponible en https://www.boe.es/diario_boe/txt.php?id=BOE-A-2017-13644 [Recuperado: 2018, 13 de septiembre].

[16] REGLAMENTO (UE) 2015/751 del Parlamento Europeo y del Consejo de 29 de abril de 2015 sobre las tasas de intercambio aplicadas a las operaciones de pago con tarjeta. Disponible en: https://eur-lex.europa.eu/legal-content/ $E S / T X T / P D F /$ ? uri=CELEX:32015R0751 $\&$ from $=E N$ [Recuperado: 2018, 13 de septiembre].

[17] SCHNEIDER, F. (2015). «Size and Development of the Shadow Economy of 31 European and 5 other OECD Countries from 2003 to 2015: Different Developments?». Journal of Self-Governance and Management Economics, vol. 3, n.․ 4, pp. 7-29.

[18] UNIÓN EUROPEA (2014). Comprender las políticas de la Unión Europea: Agenda Digital para Europa. Disponible en: https://europa. eu/european-union/file/1501/download_es?token=3/7DOFil [Recuperado: 2018,13 de septiembre]. 
Información Comercial Española

Revista de Economía

6 números anuales

Artículos originales sobre un amplio espectro de temas tratados desde una óptica económica, con especial referencia a sus aspectos internacionales

Boletín Económico de Información Comercial Española

12 números anuales

Artículos y documentos sobre economía española, comunitaria e internacional,

con especial énfasis en temas sectoriales $\mathrm{y}$ de comercio exterior

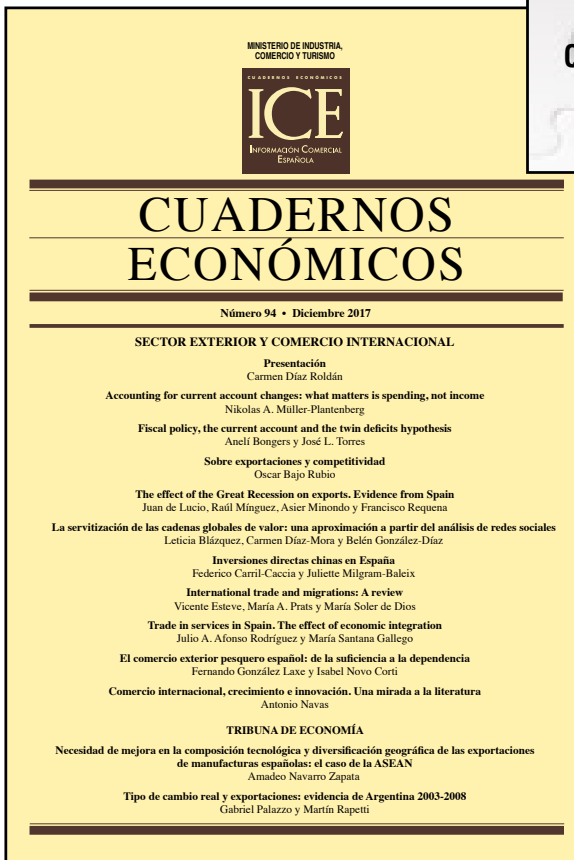

\section{Cuadernos Económicos de ICE}

2 números anuales

Artículos de economía teórica y aplicada y métodos cuantitativos, que contribuyen a la difusión y desarrollo de la investigación 